\title{
Histopathological Study of Endometrium in Patients of Perimenopausal Age Group in a tertiary care Hospital in West Bengal
}

\author{
Nabanita Chakraborty ${ }^{1}$, Rajasri Chunder ${ }^{2}$, Barnali Mukherjee ${ }^{3}$, Soham Chakraborty ${ }^{4}$ \\ ${ }_{1,3}^{13}$ Assistant Professor, Department of Anatomy, KPC Medical College \& Hospital, Kolkata, ${ }^{2}$ Professor \& Head, \\ Department of Anatomy, JIMSH, Buita, Budge Budge, Kolkata, ${ }^{4}$ Consultant Pathologist, Dr Tribedi's \& Roy Diagnostic \\ Laboratory
}

Background: Menopause is an important event in women's life and it marks the end of a woman's reproductive life. Perimenopause is the interval in which a woman 's body makes a natural shift from regular cycles of ovulation \& menstruation to irregular cycles and various forms of abnormal uterine bleeding. Dysfunctional uterine bleeding (DUB) is a very frequent complaint from women in the perimenopausal age group. The histological diagnosis of DUB and its proper management is very essential in this age group. Aims and Objective: Primary aim of our study was to identify the spectrum of histological changes that occur in the endometrium in perimenopausal age group and to identify the demographic pattern of each histological change. Materials and Methods: Fifty-two specimens of endometrial biopsy obtained from the patients in the perimenopausal age group of 40-50 years attending the Gynaecology and Obstetrics department were studied. Results: $71.15 \%$ cases of DUB was diagnosed amongst the 52 endometrial biopsy specimens in perimenopausal age group and Secretory endometrium is most common histological pattern. Conclusion: This study reflects a spectrum of endometrial histology present during perimenopausal age. This study has also highlighted the correlation of endometrial histology with final diagnoses of the patients, and this may help in diagnosis and treatment of gynaecological diseases of this specific age group in future.

Key words: Endometrial biopsy; Abnormal Uterine Bleeding; Dysfunctional Uterine Bleeding; Perimenopausal age group

\section{Access this article online}

Website

http://nepjol.info/index.php/AJMS DOI: 10.3126/ajms.v12i9.37991

E-ISSN: 2091-0576

P-ISSN: 2467-9100

Copyright (c) 2021 Asian Journal of Medical Sciences

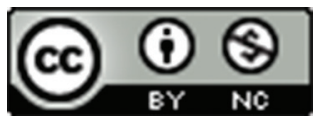

This work is licensed under a Creative Commons Attribution-NonCommercial 4.0 International License.

\section{INTRODUCTION}

Dysfunctional uterine bleeding is considered as bleeding (either excessive amount, prolonged or frequent) of uterine origin without any demonstrable pelvic pathology, complication of pregnancy or any other systemic diseases. ${ }^{1}$ This ovulatory and anovulatory bleeding is diagnosed after the exclusion of pregnancy, pregnancy-related disorders, medications, iatrogenic causes, obvious genital tract pathology and systemic conditions. Endometrial curettage and biopsy are the two most important methods for definitive diagnosis of the lesions and studies have shown that histopathological pattern of diagnosis varies with respect to age of the patients. Women of perimenopausal age group present more commonly with endometrial hyperplasia and endometrial cancer. ${ }^{2}$ Our study deals with normal histology of endometrium and its variations. Histological characteristics of endometrial biopsy material as assessed by light microscopy remain the diagnostic standard for the clinical diagnosis of endometrial pathology. ${ }^{3}$ Types of endometrial histology found in perimenopausal age group in the previous studies are secretory endometrium, proliferative endometrium, simple hyperplasia without atypia, complex hyperplasia without and with atypia, endometrial polyp, exogenous hormone induced changes in endometrium, disordered proliferative endometrium and endometrial changes in luteal phase defect. 


\section{MATERIALS AND METHODS}

The study was conducted in a tertiary care hospital after getting approval from the Institutional Ethics committee over a period of 1 year ( $1^{\text {st }}$ June, 2015- 31 ${ }^{\text {st }}$ May, 2016). The study population comprised of the perimenopausal women between 40-50 years of age, who came for endometrial biopsy as a diagnostic procedure for AUB (abnormal uterine bleeding). The informed consent was obtained from the patient. The menstrual history and age of the patient was noted. Following the endometrial biopsy, specimens from operation theatre were sent to the pathology department. Tissue sections were prepared and hematoxylin and eosin staining was done for microscopic examination. Photomicrographs of the histological slide were obtained. The results were tabulated and graphical representation was done.

\section{RESULTS}

Fifty-two patients with abnormal uterine bleeding (AUB) who underwent endometrial biopsy were included in the study. The distribution of the age of the patients diagnosed as case of Dysfunctional Uterine Bleeding (DUB) is shown in Table 1 . The mean age of diagnosis of DUB is 44.45 years with a median age of 45 years.

The final diagnoses obtained from the endometrial biopsy were as follows: $71.15 \%$ - Dysfunctional Uterine bleeding, 11.53\%- Leiomyoma, 7.69\%- Adenomyosis, $5.76 \%$ - Cervical polyp and 3.84\%- Squamous cell carcinoma of cervix (Table 2).

Amongst the patients who were diagnosed as a case of DUB, the most common histological picture that was seen Secretory endometrium $(24.32 \%)$ (Figure 1 ) followed by Proliferative endometrium (21.62\%) (Figure 2), Hormonal changes (16.21\%) (Figure 3) and Simple Hyperplasia $(13.51 \%)$ (Figure 4). Other minor histological changes are depicted in (Figure 5).

\section{DISCUSSION}

Perimenopause, also called the menopausal transition, is the interval in which a woman`s body makes a natural shift from more-or-less regular cycles of ovulation and menstruation to irregular and anovular cycles. Menopause is an important event occurring during middle age in women and represents the end of a woman's reproductive life. Perimenopause phase generally occurs at around 40 to 50 years of age where there is a wide variety abnormal uterine bleeding (AUB).

$\begin{aligned} & \text { Table 1: Age distribution and percentage of } \\
& \text { diagnosed cases of Dysfunctional Uterine } \\
& \text { bleeding }\end{aligned}$
\begin{tabular}{lcc} 
Age group & Number of DUB cases & Percentage \\
\hline $40-45$ years & 24 & $64.86 \%$ \\
$46-50$ years & 13 & $35.13 \%$ \\
\hline
\end{tabular}

\begin{tabular}{lcc}
$\begin{array}{l}\text { Table 2: Percentage and distribution of final } \\
\text { diagnosis from endometrial biopsy }\end{array}$ \\
\hline Final Diagnosis & $\begin{array}{c}\text { Number } \\
\text { of Cases }\end{array}$ & Percentage \\
\hline DUB & 37 & $71.15 \%$ \\
Adenomyosis & 4 & $7.69 \%$ \\
Leiomyoma & 6 & $11.53 \%$ \\
Squamous Cell Carcinoma Cervix & 2 & $3.84 \%$ \\
Cervical Polyp & 3 & $5.76 \%$ \\
Total number of cases & 52 & \\
\hline
\end{tabular}

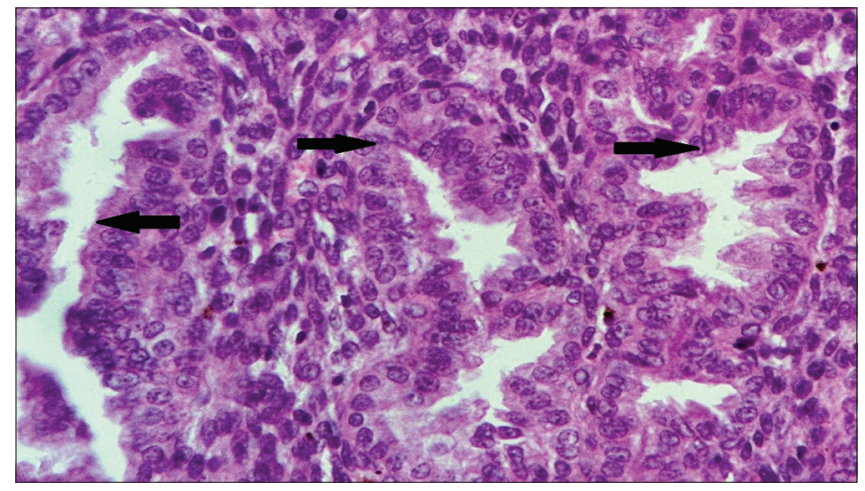

Figure 1: Secretory endometrium showing tortuous glands (marked with arrow) with dilated lumens containing secretion (H\&E, x400)

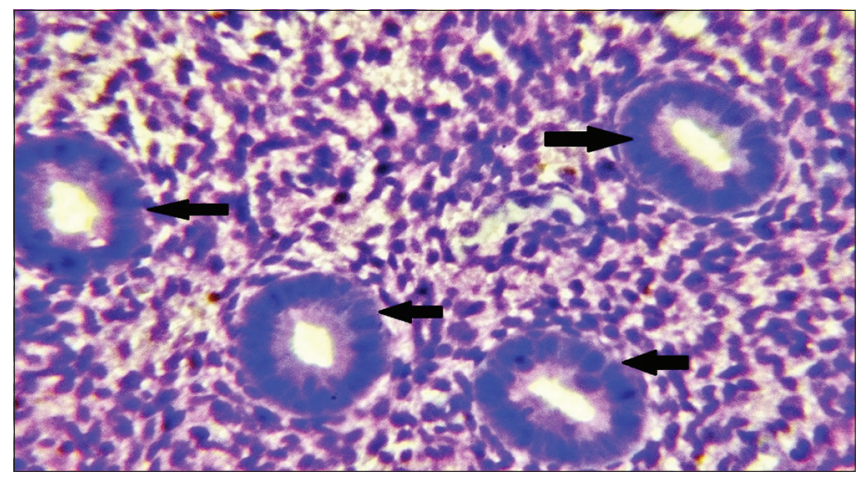

Figure 2: Proliferative endometrium showing small round glands (marked with arrow) lying in a dense stroma (H\&E, x400)

A criterion to diagnose DUB is that heavy menstrual bleeding with no underlying causes.

Our study deals with normal histology of endometrium and its variation in perimenopausal years. After approval from institutional ethics and research committee, the study was conducted over a period of one year. Endometrial biopsy specimen was collected from patients in perimenopausal 


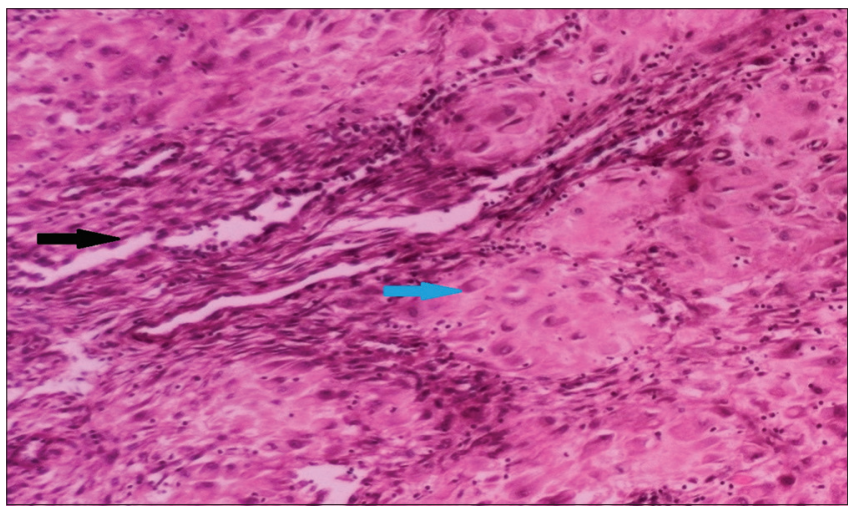

Figure 3: Endometrium with hormonal changes showing non secretory glands (marked with black arrow) lying in an edematous stroma with the stromal cells (marked with blue arrow) showing abundant eosinophilic cytoplasm (H\&E, x400)

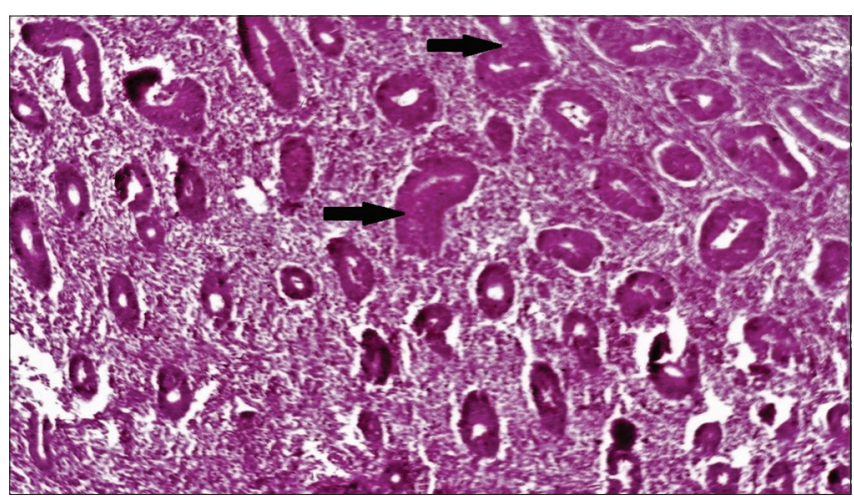

Figure 4: Endometrium with simple hyperplasia showing increased gland: stroma ratio with numerous glands (marked with arrow) showing stratification of the lining epithelium(H\&E, $x 400)$

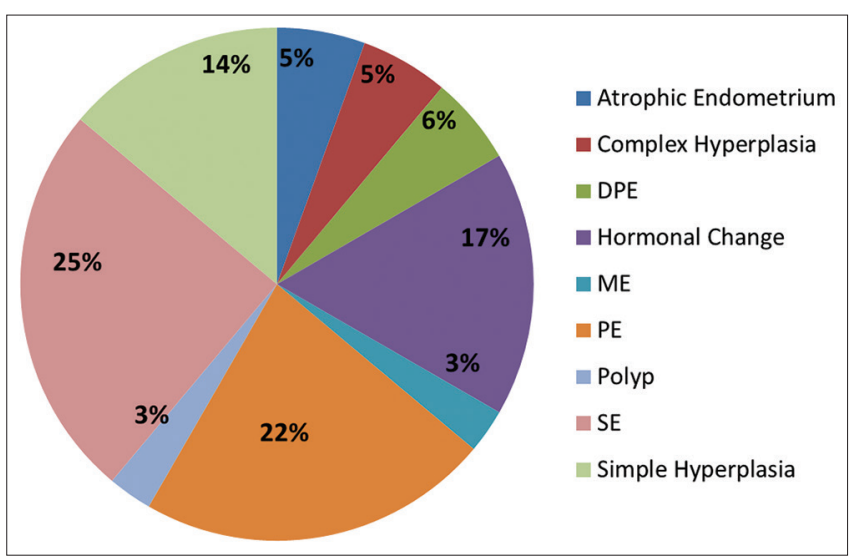

Figure 5: Distribution of types of endometrium in DUB cases Abbreviation: DPE-Disordered proliferative endometrium, ME-Menstrual endometrium, Proliferative endometrium, SE- Secretory endometrium

age group (40-50 years) who came to the department of Gynaecology and Obstetrics after getting informed written consent from the patients.

Various studies were conducted on endometrial biopsy, but the sample sizes varied. Snehkiran et al ${ }^{4}$, Kumari A et al., ${ }^{5}$ and Padmaja et al., ${ }^{6}$ conducted studies over larger population 126, 180 and 200 cases respectively. Pillai et al., did their study on 88 cases in the age group 40-50 years and reported a preponderance of proliferative endometrium in histology and a diagnosis of fibroid uterus in 55.7\%. ${ }^{7}$ Yet another study conducted by Kariappa T M et al., on larger sample size of 205 cases in a wider age range of 20-60 years. The study showed the endometrial pattern of $40 \%$ cases of proliferative endometrium followed by $31 \%$ cases of secretory endometrium in DUB patients. ${ }^{8}$

In our study we found variable histological patterns of endometrium among DUB patients. Normal cyclical endometrium was the most common finding (19 cases out of 37 cases of DUB), among which 10 cases had secretory endometrium $(24.32 \%)$, while 8 cases had proliferative endometrium (21.62\%). Jetley et al., conducted a endometrial study on 219 perimenopausal women and the endometrial pattern was similar to our study. Secretory endometrium was seen in 71 cases $(32.4 \%)$ followed by Proliferative endometrium in 67 patients (30.6\%). ${ }^{9}$ Study by Takreem et al., in 2009 revealed a predominance of simple cystic endometrial hyperplasia (66.6\%), $20.0 \%$ of adenomatous hyperplasia and $13.3 \%$ of atypical hyperplasia. ${ }^{10}$ In our study, the incidence of simple hyperplasia was $13.51 \%$ while complex hyperplasia was $5.4 \%$. Doraiswami in 2011, conducted a study on 409 patients in a wide age group range. The predominant endometrial pattern found was disordered proliferative pattern $(20.5 \%) .{ }^{11}$ Only 2 cases $(5.4 \%)$ had similar findings in our study.

Our study revealed $71.15 \%$ (37 cases) endometrial biopsy specimens diagnosed as DUB amongst 52 specimens. This was followed by leiomyoma $(11.53 \%)$ and then adenomyosis $(7.69 \%)$. Kumari et al., showed similar findings in their study on 180 specimens with $51.66 \%$ diagnosis of DUB followed by $28.88 \%$ leiomyoma and $3.88 \%$ adenomyosis in their study. ${ }^{5}$

We found 24 cases of DUB in early perimenopausal age group $(64.86 \%)$ similar to the study by Snehkiran et al., with DUB cases of $65 \%$ in early perimenopausal age group. ${ }^{4}$

\section{CONCLUSION}

In our study DUB is the most common cause of abnormal uterine bleeding in the perimenopausal age group. Normal cyclical endometrium was most common finding $(24.32 \%$ secretory endometrium followed by $21.62 \%$ proliferative endometrium) among DUB patients. Majority of previous studies revealed a preponderance of proliferative endometrium while our study revealed a secretory 
predominance. Other lesions causing perimenopausal bleeding was found to be leiomyoma and adenomyosis. Hence this study reflects a spectrum of endometrial histology present during perimenopausal age in DUB patients.

\section{ACKNOWLEDGEMENT}

The authors take this opportunity to thank Department of Anatomy \& Pathology, R G Kar Medical College \& Hospital, Kolkata for their whole hearted support for this study

\section{REFERENCES}

1. Fraser IS and Sungurtekin S. Defining menstrual disturbances. In Maclean, A and O'Brien PMS (edrs). Study group on Menstrual disorders. Royal College of Obstetricians and Gynaecologists. pp 141-152.

2. Forae GD and Aligbe JU. Histopathological patterns of endometrial lesions in patients with abnormal uterine bleeding in a cosmopolitan population. Journal of Basic and Clinical Reproductive Sciences. 2013; 2(2):101-104.

https://doi.org/10.4103/2278-960X.118649

3. Mutter GL. Diagnosis of premalignant endometrial disease. Journal of Clinical Pathology. 2002; 55(5):326-331. https://doi.org/10.1136/jcp.55.5.326

4. Snehkiran, Abhilashi K, Tiwary $B$, Sinha $S$ and Parwina $P$.
Clinicopathological observation of Abnormal uterine bleeding in peri-menopausal age female. International Journal of Clinical Obstetrics and Gynaecology.2019; 3(1): 136-138. https://doi.org/10.33545/gynae.2019.v3.i1c.23

5. Kumari $A$ and Kumar R. Abnormal uterine bleeding in perimenopausal age: An observational study. Indian J Obstet Gynecol Res. 2018;5(4):539-543.

https://doi.org/10.18231/2394-2754.2018.0121

6. Padmaja GV, Quadri SS and Kumar OS. Histomorphological profile of endometrium in perimenopausal bleeding. International Archives of Integrated Medicine. 2016; 3(7):255-259.

7. Pillai SS. Sonographic and histopathological correlation and evaluation of endometrium in perimenopausal women with abnormal uterine bleeding. Int J Reprod Contracept Obstet Gynecol. 2014;3(1):113-117. https://doi.org/10.5455/2320-1770.ijrcog20140323

8. Kariappa TM, Sathish TE and Saha A. Histopathological study of endometrium in dysfunctional uterine bleeding. The Pharma Innovation Journal. 2016; 5(1): 29-32.

9. Jetley $S$, Rana $S$ and Jairajpuri ZS. Morphological spectrum of endometrial pathology in middle-aged women with atypical uterine bleeding: A study of 219 cases. J Midlife Health. 2013; 4(4):216-220. https://doi.org/10.4103/0976-7800.122242

10. Takreem A, Danish N and Razaq S. Incidence of endometrial hyperplasia in 100 cases presenting with polymenorrhagia/ menorrhagia in perimenupausal women. J Ayub Med Coll Abbottabad. 2009; 21(2):60-63.

11. Doraiswami $S$, Johnson $T$, Rao $S$, Rajkumar A, Vijayaraghavan $\mathrm{J}$ and Panicker VK. Study of endometrial pathology in abnormal uterine bleeding. J Obstet Gynaecol India. 2011;61(4):426-430. https://doi.org/10.1007/s13224-011-0047-2

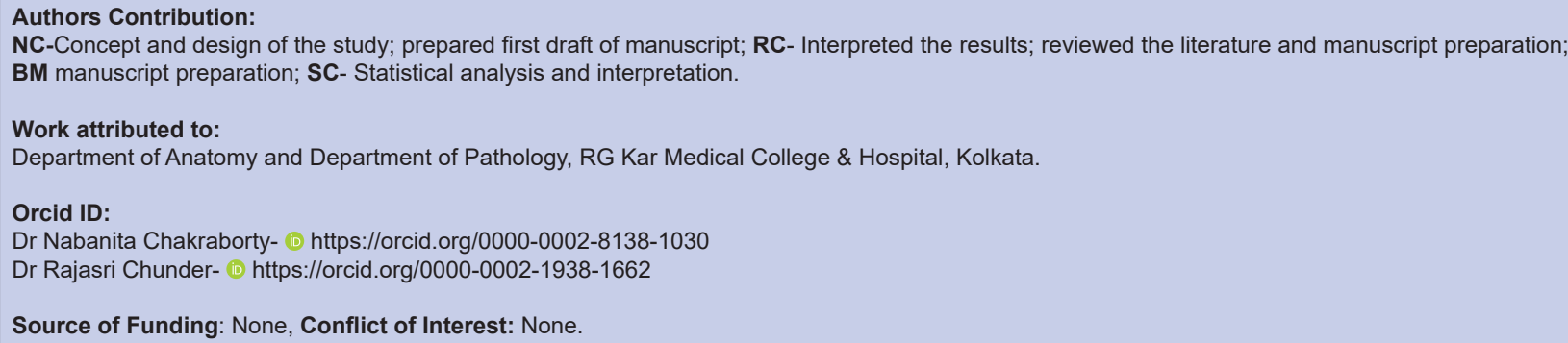

